\title{
Study on Victims of Child Abuse: A Study Conducted in Two Teaching Hospitals in Sri Lanka
}

\author{
Dharmadasa $\mathrm{LS}^{1 *}$, Kithulwaththa $\mathrm{IDG}^{2}$, Priyanath $\mathrm{DC}^{3}$, Gunathilaka $\mathrm{MAC}^{4}$, Silva $\mathrm{LSKD}^{4}$, Kumari MKJK${ }^{4}$, \\ Senanayaka TAAW ${ }^{4}$ \\ ${ }^{1}$ Office of the Judicial Medical Officer, Teaching Hospital, Anuradhapura, Sri Lanka \\ ${ }^{2}$ Department of Forensic Medicine, Faculty of Medicine, University of Kelaniya, Sri Lanka \\ ${ }^{3}$ Office of the Judicial Medical Officer, Teaching Hospital, Karapitiya, Sri Lanka \\ ${ }^{4}$ Department of Forensic Medicine, Faculty of Medicine, University of Kelaniya, Sri Lanka
}

\begin{abstract}
Introduction: Child abuse is a global public health problem and proper intervention strategies need a greater understanding of risk factors that can contribute to it. This study was conducted in order to identify the undetected contributory factors that lead to child abuse cases.
\end{abstract}

Methodology: All children (less than 18 years of age) who were brought for medico legal examination with alleged abuse to two reputed teaching hospitals during a period of 1 and $1 / 2$ years were included. Required details were obtained through an interviewer administered questionnaire after obtaining the consent.

Results: Out of the 186 children, more than $80 \%$ presented following sexual abuse and the majority $(\mathrm{n}=173)$ were females. Further, $\mathrm{n}=118$ ( $75 \%$ ) of the victims of child sexual abuse were between the age group of 13 to 15 years. Moreover, $75 \%$ of the victims of sexual abuse were from low income families. Parents of $100 \%$ of the victims of physical abuse and $60 \%$ of the victims of sexual abuse had educational qualifications below ordinary level. $82 \%$ of the victims of physical abuse were having dysfunctional family background, specially use of ethanol by parents $(65 \%)$. Parental separation was the form of family dysfunction that was associated with sexual abuse.

Conclusion: Poor income, poor parental education and dysfunctional family background could be identified as predisposing factors for child abuse. However, the association of these factors vary with different types of child abuse, thus preventive strategies should be planned accordingly.

Keywords: Child abuse, sexual abuse, low income, poor education, dysfunctional family

Received: 12 Dec 2019, Revised version accepted: 23 Dec 2021, Published: 31 Dec 2021. *Corresponding author: Dharmadasa LS, $\$ email: lakmalsamanpurad@gmail.com (D) ORCID: https://orcid.org/0000-0002-2014-8454

Cite this article as: Dharmadasa LS, Kithulwaththa IDG, Priyanath DC, Gunathilaka MAC, Silva LSKD, Kumari MKJK, Senanayaka TAAW. Study on Victims of Child Abuse: A Study Conducted in Two Teaching Hospitals in Sri Lanka. MedicoLegal journal of Sri Lanka. 2021;9(2):1-6. DOI: http://doi.org/10.4038/mljsl.v9i2.7443

Copyright: @ 2019 with the Medico-legal Journal of Sri Lanka.

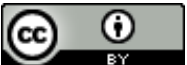

This is an open-access article distributed under the terms of the Creative Commons Attribution 4.0 International License, which permits unrestricted use, distribution, and reproduction in any medium provided the original author and source are credited.

\section{Introduction}

According to the world health organization "child abuse or maltreatment constitutes all forms of ill treatment, sexual abuse, neglect or negligent treatment, commercial or other exploitation, resulting in actual or potential harms to the child's health, survival, development or dignity in the context of a relationship of responsibility, trust or power".[1] Child abuse is a major crime in Sri Lanka, according to the amendment to the penal code in 1995 and we have established National Child
Protection Authority (NCPA) in 1999.[2] The Pediatricians of Sri Lanka, together with the College of psychiatrists and the College of Forensic Pathologists of Sri Lanka developed the National Guidelines for the management of child abuse and neglect in 2015.[3]

Incidents of child abuse varies from country to country and even in different areas in same country.[4] According to past medico-legal statistics, especially in north central province it is 
one of the rising social problems.[5] Though child abuse is common, very few cases are surfacing out worldwide[6,7] and large number of children suffer in silence. Child labor had been a common form of abuse in Sri Lanka earlier but at present child sexual abuse is on the rise.[5 Edirisinghe et al in the study of Adolescents presented for medico-legal examination with a history of sexual activity in 2008 showed that the odd's ratio of an adolescent from Anuradhapura having sex with a relative as compared to an adolescent from Ragama as 2.31 (95\%) where 1stand 2nd degree relatives were more.[8]

Even though, World Health Organization, Sri Lankan government and the relevant authorities have tried to minimize the incidents of child abuse by introducing some rules and regulations, educational and awareness programs for public, responsible people and relevant authorities, it has not come down.[9] Proper intervention against child maltreatment needs a greater understanding of risk factors that can contribute to child maltreatment and high-risk situations. Therefore, it is high time we look into the undetected contributory factors that lead to increase number of child abuse cases in Sri Lanka.

Studies have shown that there are several factors operating in the society which predispose children to abuse.[10,11] These include poverty, overcrowding, alcohol and drug addiction by the parents, disturbed childhood in either parent, recurrent disputes in the family and the absence of the care of the mother or father which is commonly known as dysfunctional family. Although there have been scattered research on child abuse in Sri Lanka, predisposing factors especially those related to local or provincial patterns have never been studied. This study was conducted to identify the risk factors for child abuse among the children presented with an allegation of abuse and to evaluate the association of risk factors with nature of abuse.

\section{Methodology}

All the children (less than 18 years of age ) who had been referred as child abuse to judicial medical officer's office of two Teaching Hospitals Anuradhapura or Ragama, during a period of 1 and $1 / 2$ years from January 2018 to July 2019 were included in this study. Historical details, examination findings and results of the investigations and referrals in order to confirm the said allegations were obtained using proforma. Consent for examination and participation was given by the parent or the guardian. In addition, assent was also given by the children who were mature enough to understand. Ethical clearance to conduct this study was obtained from the ethics review committee of the Faculty of Medicine, University of Kelaniya.

\section{Results}

Details of 186 cases from these two areas were collected and analyzed in this study.

Nature of abuse according to the geographical area

Sexual abuse was the commonest type of abuse in both geographical areas. It reflects, (n-126) $84 \%$ in Teaching Hospital Anuradhapura and, (n-31) $86 \%$ in Teaching hospital Ragama. The distribution of abuse according to the geographical area is shown in Table 01.

Table 1: Distribution of abuse according to the hospital

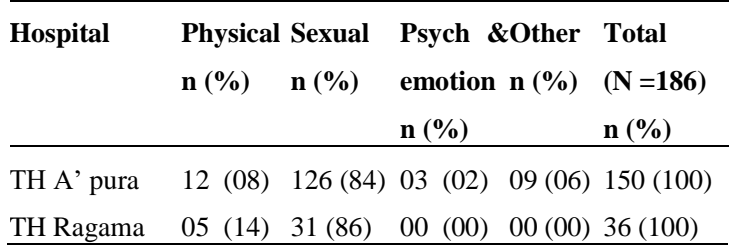

Gender distribution according to the nature of abuse

Majority of the victims were females and out of 173 females $150(87 \%)$ were victims of sexual abuse while there were only 7 (54\%) victims of sexual abuse among males. The distribution of abuse according to the sex is shown in Table 02 .

Age group and distribution of type of the abuse Most vulnerable age group for both physical $(\mathrm{n}=07$, $41 \%)$ and sexual $(\mathrm{n}=118,75 \%)$ abuse was $13-15$ years followed by $10-12$ years for physical abuse $(\mathrm{n}=04,23 \%)$ and 16 to 18 years for sexual abuse $(\mathrm{n}=18,12 \%)$. The distribution of abuse according to the age is shown in Table 02 .

\section{Living area and distribution of type of abuse}

Majority of victim of physical (n-9, 53\%) and Sexual (n-114, 73\%) abuse were from rural areas.

The distribution of living area according to the age is shown in Table 02.

Nature of abuse according to the monthly income of the family

All the physically abused cases were reported among the families with an income less than Rs. 40,000.00 per month. Seventy five percent $(n=118)$ victims of sexual abused were from families with an income of less than Rs. 40,000.00 per month. The distribution 
of abuse according to the monthly income is shown in Table 02.

\section{Education level of the caretaker and distribution} of the nature of abuse

When the parental education level is poor (up to grade 10) there is a high tendency of both physical $(n=17,100 \%)$ and sexual abuse $(n=94,60 \%)$. There is a significant association of poor parental education with tendency to have sexual abuse $(\mathrm{P}=0.0001)$.

The distribution of abuse according to the education level of the caretaker is shown in Table 02 .

Table 02: Distribution of the types of abuse with Demographic factors

\begin{tabular}{|c|c|c|c|c|c|c|}
\hline & Character & $\begin{array}{r}\text { Physical } \\
\text { n }(\%)\end{array}$ & $\begin{array}{r}\text { Sexual } \\
\text { n }(\%)\end{array}$ & $\begin{array}{r}\text { Psych \& } \\
\text { emotion } \\
\text { n (\%) }\end{array}$ & $\begin{array}{l}\text { Other } \\
\text { n }(\%)\end{array}$ & $\begin{array}{r}\text { Total } \\
\mathrm{N}=186\end{array}$ \\
\hline \multirow{2}{*}{ Sex } & Male & $06(46)$ & $07(54)$ & $00(00)$ & $00(00)$ & 13 \\
\hline & Female & & $150(87)$ & $03(02)$ & $09(05)$ & 173 \\
\hline \multirow{6}{*}{$\begin{array}{l}\text { Age } \\
\text { (years) }\end{array}$} & $1-3$ & 00 & $02(01)$ & $00(00)$ & 00( & 02 \\
\hline & $4-6$ & $00(00)$ & $04(20)$ & $00(00)$ & 00( & 04 \\
\hline & $7-9$ & 03 (18) & $09(06)$ & $00(00)$ & 00 & 12 \\
\hline & $10-12$ & $04(2$ & $06(04)$ & $00(00)$ & 00( & 10 \\
\hline & 13-15 & $70(4$ & $118(75)$ & $03(100)$ & 09 (100) & 137 \\
\hline & $16-1$ & & 18 & & & 21 \\
\hline \multirow{3}{*}{$\begin{array}{l}\text { Living } \\
\text { area }\end{array}$} & Urban & $05(2$ & $15(9)$ & $00(00)$ & & 23 \\
\hline & Semi urban & 03 (18) & $28(18)$ & $00(00)$ & 00 & 31 \\
\hline & Rural & $09(53) 1$ & & $03(1$ & 06 & 132 \\
\hline \multirow{7}{*}{$\begin{array}{l}\text { Income } \\
\text { (Rs) }\end{array}$} & $<10$ & & 33( & & & 42 \\
\hline & 10-20, & $00(00)$ & 27 (17) & $00(C$ & 00 & 27 \\
\hline & 20-30, & 03 (18) & $24(15)$ & $00(00)$ & 00 & 27 \\
\hline & $30-4$ & $11(($ & $34(22)$ & $00(00)$ & & 48 \\
\hline & $40-50,000$ & $00(00)$ & $21(13)$ & $03(100)$ & $00(00)$ & 24 \\
\hline & $>\mathbf{5 0 , 0 0 0}$ & $00(00)$ & $15(10)$ & $00(00)$ & & 15 \\
\hline & Other & & $03(02)$ & & & 03 \\
\hline \multirow{5}{*}{$\begin{array}{l}\text { Educat } \\
\text { onal } \\
\text { level }\end{array}$} & iNone & $00(($ & $18(11)$ & 00( & 00 & 18 \\
\hline & Grade 1- & & $15(10)$ & 00( & & 15 \\
\hline & Grade 6-10 & $17(100)$ & $61(39)$ & $00(00)$ & 03 & 81 \\
\hline & $\mathrm{O} / \mathrm{L}$ & $00(00)$ & $48(30)$ & $03(100)$ & 06 & 5 \\
\hline & $\mathrm{A} / \mathrm{L}$ & $00(00)$ & $15(10)$ & $00(00)$ & $00(00)$ & 15 \\
\hline
\end{tabular}

Association of nature of abuse with dysfunctional family setup

Out of the 17 victims of physical abuse $82 \%$ were having a dysfunctional family set up. Further, at detailed analysis of the nature of the family dysfunction among these children who suffered physical abuse, it was revealed that out of the 15 victims who were cared by parents abusing drugs or alcohol, $11(73 \%)$ had been subjected to physical abuse. Out of the 57 victims from dysfunctional families $43(75 \%)$ had experienced sexual abuse while out of the 129 victims from non-dysfunctional families $114(88 \%)$ had faced sexual abuse. The association is significant $(\mathrm{p}=0.03)$.

Factors affecting dysfunctional family set up were multiple in most victims. However, when the major factor associated with a particular victim is considered, out of the total of 17 physical abuse children $65 \%$ were associated with alcohol or drug abuse of the care givers. Though there was a less chance of sexual abuse among the dysfunctional families, the detailed analysis revealed that out of the 43 cases of sexual abuse from the children of dysfunctional family setup, majority 30 (70\%) were having parental separation as the dysfunctional status. There is a significant association $(\mathrm{P}=0.000)$ of parental separation with child sexual abuse among the various causes considered as dysfunctional status. Association of nature of abuse with dysfunctional family setup is shown in Table 03 .

Relationship of the abuser and type of abuse When the relationship of the abuser was considered majority (64\%) it was a non-relative know person for sexual abuse. (This group of abusers includes boyfriends, teacher, neighbors etc. while $90 \%$ of them were boyfriends. $82 \%$ of the children with physical abuse were subjected to abuse by their fathers. Relationship of the abuser and type of abuse is shown in Table 03.

Table 03: Distribution of type of abuse with family factors.

\begin{tabular}{|c|c|c|c|c|c|}
\hline & $\begin{array}{c}\text { Physical } \\
\text { n (\%) }\end{array}$ & $\begin{array}{r}\text { Sexual } \\
\text { n }(\%)\end{array}$ & $\begin{array}{r}\text { Psych \& } \\
\text { emotion } \\
\text { n (\%) }\end{array}$ & $\begin{array}{l}\text { Other } \\
\text { n }(\%) \\
\text { n=186 }\end{array}$ & $\begin{array}{r}\text { Tot } \\
\text { al }\end{array}$ \\
\hline \multicolumn{6}{|l|}{ Family } \\
\hline Dysfunctional & $14(82)$ & $43(27)$ & $00(00)$ & $00(00)$ & 57 \\
\hline None-dysfunctional & $03(18)$ & $114(73)$ & $03(100)($ & $09(100)$ & 129 \\
\hline \multicolumn{6}{|l|}{ Dysfunctional F } \\
\hline /Father A & 00( & 03 & 00 & $00(00)$ & 03 \\
\hline Father-AFH & $00(C$ & $06(14)$ & $00(00)$ & $00(00)$ & 06 \\
\hline Alcohol/drug abuse & $11(79)$ & $04(09)$ & $00(00)$ & $00(00)$ & 15 \\
\hline \multicolumn{6}{|l|}{ Relationship } \\
\hline Father & $14(82)$ & $04(02)$ & 03(100) & $00(00)$ & 21 \\
\hline ather & ) & 09 & $00(00)$ & $00(00)$ & 09 \\
\hline & ) & $27(17)$ & $00(00)$ & $06(67)$ & 36 \\
\hline Non- & $00(C$ & 101(64) & $00(00)$ & $03(33)$ & 104 \\
\hline Non- & 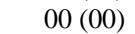 & $10(C$ & $00(00)$ & $00(00)$ & 10 \\
\hline Grand pa & $00(00)$ & $03(02)$ & $00(00)$ & $00(00)$ & 03 \\
\hline Non-Relative G & $00(00)$ & $03(02)$ & $00(00)$ & $00(00)$ & 03 \\
\hline
\end{tabular}

\section{Discussion}

Understanding the risk factors associated with child abuse and neglect is of utmost importance in developing strategies for effective prevention as well as for early intervention in affected. Further, identifying families who would most likely to benefit from additional support is also a need. These risk factors may vary from country to country. [12] However, presence of risk factors in a family does not necessarily indicate child abuse. [12] Risk factors are not causes of child abuse. Thus presence 
of risk factors should not be given a priority in formulating a medico-legal opinion in child abuse.

The study revealed that the sexual abuse was the commonest form of child maltreatment in both geographical areas; Teaching Hospital Anuradhapura and Teaching Hospital, Ragama. According to the statistics of the National Child Protection Authority of Sri Lanka, out of the 8,548 complaints received during the year 2017, there had been 481 sexual molestation cases, 284 cases of serious sexual abuse and 322 rapes of minor girls under 18 which amounts to $13 \%$ of total complaints.[13] Study findings showed a drastic difference where more than $80 \%$ (n-157)of the referred cases are child sexual abuse. This indicates that either most of these cases are not recorded in National Child Protection Authority or other forms of cruelty to children that are reported to NCPA are not referred to a Judicial Medical Officers in these two teaching hospitals but most probably to centers in Colombo, which are closer to NCPA.

In our study majority of the victims were females. $87 \%$ among them were victims of sexual abuse while $53 \%$ among in males were such victims. It is reported that worldwide prevalence of child sexual abuse is $7.9 \%$ in males and $19.7 \%$ in females.[14] Our figures show four folds of global percentage in females and nine folds of global percentage in males. This discrepancy is because our victims are reported cases and not picked up at a community survey. This highlights the under reporting of other types of abuse than sexual abuse.

Most vulnerable age group for both physical and sexual abuse was $13-15$ years. Similarly, according to the age wise distribution of child sexual abuse among females in, Karnataka it was evident that girls of 14 to 17 are more vulnerable.[15]In a global report on violence, it was observed that overall prevalence of physical violence is lower, but is notably higher for both boys and girls of the age group of 8 to 11.[16] However, the commonest form of child physical abuse among the group considered for child physical abuse was abuse or harassment by peers. In our study group physical harassment by peers were not included. Again, the explanation is even though such abuse is prevalent in the community, obvious non referral of such cases for medico legal examination.

Majority of the victims of both physical and sexual abuse were from rural areas. This can be explained from the fact that the $74 \%$ of our group are victims presented to Teaching Hospital, Anuradhapura where the coverage area is mostly rural. Similarly, in a study done in USA both physical and sexual abuse was equally distributed among rural and urban areas, though physical neglect was slightly high in rural USA.[17]

All physical abuse victims and $75 \%$ of the sexual abuse victims were from families with monthly income of less than Rs. 40,000.00. It is reported that poverty and economic hardships are closely associated with child abuse and neglect.[18]However, it is a challenge to make a statement on the association of poverty and child maltreatment in this study since majority of children who seek care at Government hospitals where this study was carried out were from poor socio economic background. Families that are more privileged may seek the medical attention at private sector even without going through the bothersome judicial process. This fact has been appreciated by studies conducted in other countries as well. It is reported that even though the chances of poor families having contact with social care workers are high, that is not the only reason to have higher chances of reporting. [19] There are four times more chances of the parents of these families having mental health issues and other risk factors. [19]On the other hand, it is shown in studies that financial support have led to significantly fewer reports of child neglect.[20]

Poor education of parents is significantly associated with child maltreatment.[21] On the other hand, educational intervention on parenting had drastically reduce child maltreatment.[23]In this study, all children with physical abuse were from families with parental education less than ordinary level. There were majority of sexual abuse victims also coming under this group. This has to be interpreted together with the relationship of the abuser.

In our study, most of the assailants of physical abuse were fathers and for sexual abuse it was a nonrelated known person or boyfriend. Further, studies on filicide reveals that abusive perpetrators are young, immature, uneducated and having violent and chaotic background.[22]

When it comes to sexual abuse, parents have a major role in prevention of child sexual abuse. Parent supervision, monitoring, and involvement as well as love and care can play a significant role in protection of their children from unwanted relationships. It is reported in literature that having an uneducated mother is associated with sexual abuse of their children.[24,25] 
Dysfunctional family background especially ethanol or substance abuse is strongly associated with child physical abuse. In our study, $82 \%$, of victims of physical abuse were from the dysfunctional family and $79 \%$ has strong relationship with alcohol and drug abuse. This is a globally accepted fact and a number of studies have shown that parental alcohol abuse is a significant contributory factor to child maltreatment specially physical and sexual abuse.[26] On the other hand, many studies have shown that experiencing maltreatment as a child is associated with marked increase in the risk of being an alcoholic as an adult.[27] This confirms the fact that child maltreatment is a vicious cycle. An individual who got subjected to abuse in childhood will become an abuser himself in later life. In our study $73 \%$ of victims of sexual abuse were from nondysfunctional family. This can be explained from the fact that majority of the families in this country are non- dysfunctional and it is a representation of the family characters of the society. On the other hand, though there is no association of dysfunctional family set up with sexual abuse, out of the victims of sexual abuse who are having dysfunctional family, parental separation was the main reason of family dysfunction. Living in a single parent family is identified as a risk factor for most types of child maltreatment including lifetime sexual abuse.[28]

Further, abusers are not the family members in sexual abuse. According to the findings of this study $65 \%$ of abusers were non relative known people.

\section{Limitations}

The study was conducted among the victims who had been referred for medico- legal examination and therefore, the true picture in the community is not showcased here.

\section{Conclusions}

The study revealed several risk factors associated with child abuse including low family income, substance abuse and poor education level of the caretakers. Majority of abusers were known to the child; father in physical child abuse and boyfriend in sexual abuse. Study showed most affected age group for both physical and sexual child abuse is between 13-15 years.

\section{Disclosure statement}

Conflicts of interests: The author declares that they have no conflicts of interest.

Funding: None

\section{References}

1. Etienne GK, Linda LD, James AM, Anthony BZ, Rafael L, World report on violence and health [Internet]. Geneva: World Health Organization; 2002. Available from: https://www.who.int/violence_injury_preventio n/violence/world_report/en/full_en.pdf

2. Silva HD, A coordinated National plan of action in child protection in Sri Lanka. Proceedings of 12th Asia Pacific Congress of Paediatrics and 2nd Asia Pacific Congress of Paediatric Nursing. 2007; 1(1):116

3. Fernando AD, National Guideline for Management of Child Abuse and Neglect Multi - sectoral Approach. 1st ed. Sri Lanka: Sri Lanka College of Paediatricians and Plan Sri Lanka; 2014.

4. Stark M. clinical forensic medicine. Newjersey: Humana press; 2005;161-62

5. Colombage SM, Dassanayaka PB and Waidyaratna DL, 2005. A study on child abuse in Anuradhapura, Colombo South and Ratnapura. Sri Lanka Journal of Forensic Medicine Science Law, 2005;11():22

6. Martin E, Silverstone P. How Much Child Sexual Abuse is "Below the Surface," and Can We Help Adults Identify it Early?. Frontiers in Psychiatry. 2013;4.

7. Lau J, Liu J, Yu A, Wong C. Conceptualization, reporting and underreporting of child abuse in Hong Kong. Child Abuse \& Neglect. 1999;23(11):1159-1174.

8. Edirisinghe PAS, Perera WNS, Paranitharan P, Perera BPP, Samarasekara A, Waidyrathna DL, Jayasena AS. A comparative descriptive study on adolescents presented to Ragama and Anuradhapura teaching Hospitals for medicolegal examination with history of 'sexual activity' A collection of Research papers on Adolescent Sexual and Reproductive Health Ragama: Faculty of Medicine, University of Kelaniya \& Plan International; 2008. p. 9-36. http://repository.kln.ac.lk/handle/123456789/1 1723

9. National Child Protection Authority. Annual Report

2013.https://www.parliament.lk/.../annualreport-national-child-protection-authority2013.p

10. U.S. Department of Health and Human Services. Administration on Children, Youth and Families, Children's Bureau. 2016. Child maltreatment 2014 [online] Available from: http://www.acf.hhs.gov/sites/default/files/cb/c m2014.pdf

11. Doidge JC, Higgins DJ, Delfabbro P, Segal L. Risk factors for child maltreatment in an 
Australian population-based birth cohort. Child Abuse Neglect. 2017;64:47-60.

12. Goldman J, Salus M, Wolcott D \& Kennedy K. What factors contribute to child abuse and neglect? A coordinated response to child abuse and neglect: The foundation for practice. Washington D.C.: Office on Child Abuse and Neglect 2003

13. Gunaratna G. S. Sri Lanka: Sri Lanka Child authority receives over 8,500 complaints of child abuse in 2017 [Internet]. Colombopage.com. [cited 13 June 2021]. Available from: http://www.colombopage.com/archive_17B/De c11_1513003596CH.php

14. Wihbey J. Global prevalence of child sexual abuse. Journalist Resource. [Last on Aug and Updated on 2011 Nov 15]. Available from: https://journalistsresource.org/criminaljustice/global-prevalence-child-sexual-abuse/

15. Bangalore: Government of Karnataka Police department; 2012. Crime in Karnataka 2012. Available from: http://ncrb.nic.in/CD.CII2012/Statistics2012.pd $\mathrm{f}$

16. Global Report - The Global Report [Internet]. The Global Report. [cited 13 June 2021]. Available from: http://globalreport.knowviolenceinchildhood.or g/global-report-2017/

17. Carsey School of Public Policy | UNH [Internet]. Carsey School of Public Policy | UNH. [cited 13 June 2021]. Available from: https://carsey.unh.edu/

18. Lefebvre R, Fallon B, Van Wert M, Filippelli J. Examining the Relationship between Economic Hardship and Child Maltreatment Using Data from the Ontario Incidence Study of Reported Child Abuse and Neglect-2013 (OIS-2013). Behavioral Sciences. 2017;7(4):6

19. Jonson-Reid M. Drake N, Kohl PL. Is the overrepresentation of the poor child welfare caseloads due to bias or need? Children and
Youth Services Review. 2009;31(3):422-7. doi: 10.1016/j.childyouth.2008.09.009.

20. Raissian K, Bullinger L. Money matters: Does the minimum wage affect child maltreatment rates? Children and Youth Services Review. 2017;72:60-70.

21. Almuneef M, Alghamdi L, Saleheen H. Family profile of victims of child abuse and neglect in the Kingdom of Saudi Arabia. Saudi Medical Journal. 2016;37(8):882-8.

22. Kauppi A, Kumpulainen K, Karkola K, Vanamo T, Merikanto J. Maternal and paternal filicides: a retrospective review of filicides in Finland. $\mathbf{J}$ Am Acad Psychiatry Law. 2010;38(2):229-38.

23. Hosravan S, Sajjadi M, Moshari J, Barzegar SS. The Effect of Education on the Attitude and Child Abuse Behaviors of Mothers with 3-6 Year Old Children: A Randomized Controlled Trial Study. Int J Community Based Nurs Midwifery. 2018 Jul;6(3):227-38.

24. Fergusson DM, Mcleod GFH, Horwood LJ. Childhood sexual abuse and adult developmental outcomes: Findings from a 30year longitudinal study in New Zealand. Child Abuse Neglec2013; 37(9):664-74.

25. Hecht DB, Hansen DJ.The environment of child maltreatment: Contextual factors and the development of psychopathology. Aggression and Violent Behavior 2001; 6(5):433-57.

26. Tamutienè I. Alcohol-related child maltreatment: Reports to the Child Rights Protection Service in Kaunas municipality. Nordisk Alkohol Nark. 2018 Feb;35(1):9-23.

27. Xiao Q, Dong M, Yao J, Li W, Ye D. Parental Alcoholism, Adverse Childhood Experiences, and Later Risk of Personal Alcohol Abuse among Chinese Medical Students. Biomedical and Environmental Sciences. 2008;21(5):41119.

28. Tran N, van Berkel S, van IJzendoorn M, Alink L. Child and Family Factors Associated With Child Maltreatment in Vietnam. Journal of Interpersonal Violence. 2018;36(5-6):NP2931NP2953. 